\title{
APRESENTAÇÃO \\ DOSSIÊ: PROCESSO DE ESCOLARIZAÇÃO, FAMÍLIAS E DIVERSIDADE
}

\author{
Silvia Regina Ricco Lucato SIGOLO ${ }^{1}$
}

Luciana Ponce Bellido GIRALDI ${ }^{2}$

Este número apresenta o dossiê temático: Processo de escolarização, famílias $e$ diversidade, organizado pelo Grupo de Estudos e Pesquisa "Desenvolvimento e Educação no Contexto da Família e da Escola" (GPDEFE), da Universidade Estadual Paulista (UNESP).

Os autores deste dossiê propõem discussões ancoradas em teorias e pesquisas com fundamento em diferentes áreas, tais como a pedagogia, a psicologia e a sociologia, as quais compreendem a escola em interação com outros ambientes e dentro das pertenças atuais que permeiam e acrescentam à organização do campo educacional no Brasil, na Espanha e em Portugal.

Ainda é incomum se analisar o desenvolvimento dos estudantes de maneira sistêmica. As evidências se apresentam na ausência de rotinas de avaliação e de práticas de intervenção que focalizem famílias e escolas como contextos interdependentes de desenvolvimento e de aprendizagem das crianças. Os contextos familiares e escolares das crianças são ambientes de aprendizagem e cada um deles desempenha papéis complementares (não simétricos). HooverDempsey, Whitaker e Ice $(2010)^{3}$ destacam uma questão importante na perspectiva da teoria dos sistemas ecológicos, que é a do significado único da contribuição que cada um dos contextos oferece para a aprendizagem e desenvolvimento das crianças e asseveram que algumas destas influências não são facilmente replicadas ou substituídas por proposições do outro sistema envolvido. Desta forma, há uma defesa incondicional do significado e especificidade das funções de cada um dos contextos família e escola para o processo de aprendizagem e desenvolvimento de escolares.

\footnotetext{
${ }^{1}$ Universidade Estadual Paulista (Unesp), Faculdade de Ciências e Letras, Araraquara - SP - Brasil. Professora do Departamento de Psicologia da Educação. E-mail: sigolo@fclar.unesp.br

${ }^{2}$ Universidade Sagrado Coração (Usc), Bauru - SP - Brasil. Docente. Pós-doutoramento na Fundação Carlos Chagas (FCC) E-mail: luluponce@ gmail.com.

${ }^{3}$ HOOVER- DEMPSEY, K. V.; WHITAKER, M. C.; ICE, C.L. Motivation and commitment to family-school partnerships. In: CHRISTENSON, S. L.; RESCHLY, A. L. (Ed.). Handbook of school-family partnerships. London: Routledge, 2010. p.30-60.
} 
Além disso, nas últimas décadas foi possível reconhecer que as políticas educacionais de todo o mundo fracassaram ao estender a todas as crianças a educação obrigatória (BUENO, 2008) ${ }^{4}$. E teve início a um movimento amplo em defesa da inclusão social envolvendo necessariamente um processo de relações recíprocas entre as pessoas excluídas e a sociedade em geral, no sentido de construção de condições de vida mais dignas a todos os envolvidos, gozando de direitos idênticos (MENDES, 2006) ${ }^{5}$.

Assim, no campo da educação este movimento se caracteriza pela defesa de educação para todos aqueles que estiveram historicamente alijados deste processo, como por exemplo, os alunos que apresentavam alguma deficiência, cuja escolarização aconteceu, por um espaço significativo de tempo, em sistemas de ensino paralelos, sejam em classes especiais, sejam em escolas e instituições especializadas. Com o paradigma da inclusão escolar, este contingente de alunos estaria necessariamente fazendo parte do ensino comum ${ }^{6}$ e, consequentemente, provocando uma revisão na função da escola e no modo de conceber o ensino e os alunos que fazem parte dela. Desta forma, começaria a se desconstruir os critérios para a composição das classes escolares com base em critérios de homogeneidade.

Desta perspectiva, parece unânime que a posição em defesa da inclusão escolar seja colocada para todas as crianças indistintamente e advoga o compromisso com a flexibilidade dos programas de ensino e a busca de novas metodologias para o desenvolvimento da aprendizagem de conteúdos específicos para o atendimento adequado das necessidades educacionais.

As contribuições trazidas pelos estudos aqui apresentados podem ser organizadas em dois eixos temáticos. O primeiro teve o intuito de discutir a escola frente aos diferentes desempenhos escolares induzidos em um artigo por diferenças culturais entre os alunos e em outro, pelas dificuldades expressas no baixo desempenho escolar. O segundo eixo temático se ocupou centralmente de medidas legais que impactaram o ambiente escolar, uma delas recente como o ingresso de alunos de seis anos ao Ensino Fundamental a partir da legislação que define o ensino fundamental de nove anos, e outra, não tão recente, que trata da defesa da

${ }^{4}$ BUENO, J. G. S. As políticas de inclusão escolar: uma prerrogativa da educação especial? In: BUENO, J. G. S.; MENDES, G. M. L.; SANTOS, R. A. (Org.). Deficiência e escolarização: novas perspectivas de análise. Araraquara: Junqueira \& Marin; Brasília: CAPES, 2008.

${ }^{5}$ MENDES, E. G. A radicalização do debate sobre inclusão escolar no Brasil. Revista Brasileira de Educação ANPED, Rio de Janeiro, v.11, n.33, p.387- 405, 2006.

${ }^{6}$ É preciso esclarecer que em momentos anteriores, na história da Educação Especial, durante o paradigma de integração há registros de inserção de alunos com deficiência no ensino comum. Ver Bueno (2008) e Mendes (2006) 
inclusão de todos os alunos na escola básica, implicando na discussão dos pressupostos do movimento inclusivo, na revisão de concepções e práticas docentes e de estratégias metodológicas frente a alunos que apresentam necessidades educacionais especiais.

Neste contexto, o primeiro artigo foi escrito pela professora Teresa Seabra e intitulado de "Relação das famílias com a escolaridade e sucesso escolar: comparação entre famílias de origem cabo-verdiana, origem indiana e autóctones". O texto parte da percepção comum entre muitos professores sobre a distinção dos desempenhos dos alunos associada à abrangência do apoio familiar que seria recebido por eles. Frente a isso, a investigadora organizou uma pesquisa empírica com sujeitos oriundos de diferentes origens nacionais e concluiu que o apoio familiar não seria um fator determinante às situações de sucesso ou fracasso escolar, mas teria reflexos pontuais em atividades escolares, tais como a realização das tarefas de casa, estabelecimento de diálogos sobre a unidade de ensino, apoio frente a possíveis dificuldades de aprendizagem e presença em reuniões escolares.

O texto "Olhares infantis: o baixo desempenho acadêmico, a escola e a família", escrito por Gabriela Maffei Moreira Malagolli, Keila Hellen Barbato Marcondes e Luciana Ponce Bellido Giraldi, congregou experiências de alunos sobre situações de fracasso escolar vivenciadas e expostas pelas próprias crianças em diferentes pesquisas. Trouxe como contribuição, o agrupamento de perspectivas dos estudantes de um quinto ano, os quais, em geral, raramente puderam ser ouvidos.

O terceiro texto escrito por Caroline Raniro e Flávia Roberta Velasco Campos, "Ingresso no ensino fundamental aos seis anos? O que dizem as crianças e seus pais" teve o intuito de trazer a percepção de crianças como um eixo central de discussão, neste caso, sobre as alterações que se fizeram presentes no âmbito escolar ao anteciparem a idade de ingresso ao Ensino Fundamental. Os pais também foram chamados a contribuir com esta pesquisa ao apresentarem as percepções que tal medida política trouxe às relações estabelecidas pelos familiares e alunos com a escola. Trata-se de uma temática de pesquisa recente, que ainda conta com poucas contribuições; logo este texto pretende ampliar debates ao trazer experiências de sujeitos que passaram pela experiência de ingresso ao Ensino Fundamental aos seis anos de idade.

Por meio de um paralelo entre a educação, a aprendizagem e o desenvolvimento humano, Vera Lúcia Messias Fialho Capellini e Kátia Fonseca Abreu, em “A escola inclusiva: 
seus pressupostos e movimentos" organizaram uma análise teórica sobre a escola inclusiva, compreendendo discussões e debates atuais sobre o tema com vista à constituição de uma cultura inclusiva.

O quinto artigo intitulado "O modelo de salas de recursos multifuncionais: avanços e retrocessos de uma realidade em construção", de autoria de Saulo Fantato Moscardini e Adriana Maria Leone Alves Oliveira, focalizou também o processo de inclusão em momentos distintos nos últimos anos. Versaram sobre o funcionamento de Salas de Recursos Multifuncionais em um município polo de formação para o Programa Educação Inclusiva: Atenção à Diversidade. Apesar de se tratar de informações que foram coletadas com aproximadamente seis anos de diferença, as mudanças identificadas pelos pesquisadores se limitaram aos aspectos organizacionais, o que denunciaria a ausência da potencialização da aprendizagem dos alunos com deficiência.

Para finalizar, Yolanda Muñoz Martínez e Nuria Cordero Muñoz contribuíram com este dossiê por meio do texto: "El aprendizaje cooperativo como metodología para el desarrollo de una escuela inclusiva", que congrega o relato de uma experiência metodológica de aprendizagem colaborativa. Tenciona apresentar ferramentas para que os professores possam empregá-las em suas aulas.

A leitura dos artigos aqui apresentados resulta na certeza de que a escola e as experiências promovidas em torno dela, são preocupações constantes de pesquisas comprometidas com a educação, num exercício intenso de debates e questionamentos sobre os diferentes contextos que perpassam escolas e os sujeitos que a compõem em conjunções diversas.

\section{Como referenciar esta apresentação}

SIGOLO, Silvia Regina Ricco Lucato.; GIRALDI, Luciana Ponce Bellido. Apresentação Dossiê: Processo de escolarização, famílias e diversidade. Doxa: Rev. Bras. Psicol. Educ., Araraquara, v.19, n.1, p. 80-83, jan./jun. 2017. ISSN: 1413-2060. 